\title{
Characterization of NPM1 and FLT3-ITD Mutations in Iraqi Patients with AML
}

\author{
Hussam R Hamed ${ }^{1}$, Rakad M.Kh AL-Jumaily², Areej E. Kadhom ${ }^{3}$ \\ ${ }^{1}$ Scholar Researcher, ${ }^{2}$ Assistant Professor, Department of Biology, College of Science, University of Baghdad, \\ Baghdad, Iraq, ${ }^{3}$ Scholar Researcher, Department of Laboratory, Baghdad Teaching Hospital, Medical City Center, \\ Baghdad, Iraq
}

\begin{abstract}
Acute myeloid leukemia is a malignant disease results from mutation in a multipotent haemopoietic stem cell. The study aimed to investigate NPM1 and FLT3-ITD mutations in Iraqi patients with AML and correlate results with other clinical and laboratory findings. Fifty-eight AML patients, admitted to Baghdad Teaching Hospital from October 2019 till March 2020 in addition to 25 normal controls, were included in the study. A detailed history, laboratory investigations including FLT3-ITD and NPM1 mutations were collected from and analyzed. FLT3-ITD was detected in $17.24 \%$ of patients, NPM1 mutation in $10.34 \%$. Most of the patients are presented with pallor. FLT3-ITD mutation had a higher blast cell count (74\%) while NPM1 mutation had higher WBCs count.

Conclusion: AML is common in middle age group, patients with NPM1 mutation had significantly higher WBCs count while patients with FLT3-ITD mutation have higher blast percentage compared with nonmutated patients.
\end{abstract}

Keywords: $A M L, N P M 1, F L T 3$.

\section{Introduction}

Acute myeloid leukemia (AML) is characterized by clonal explanation of differentiated myeloid precursors which results in bone marrow failure. ${ }^{1}$ Fundamentally, the investigation of the genome profile in AML has Changed the approach of patients with AML. AML Patients are regularly tested for the existence of FMSrelated tyrosine kinase 3 (FLT3) and Nucleophosmin 1 (NPM1) gene mutations. ${ }^{2}$ NPM1 is a predominantly nucleolar of protein with important homeostasis and cell growth functions, including regulation of ribosome biogenesis and response of stress. ${ }^{3}$ Disruption of NPM1, either by chromosomal translocation or mutation, disturbs its normal function as a transporter protein leading to the notion that NPM1 mutation plays a role

\footnotetext{
Corresponding Author:

Hussam R. Hamed

Scholar Researcher, Department of Biology, College of Science, University of Baghdad, Baghdad, Iraq e-mail: hussamrabeea9@gmail.com
}

in early leukemogenesis as recorded in about 35 percent of AML cases. ${ }^{4}$

FLT3 encodes a tyrosine kinase receptor preferentially expressed in hematopoietic progenitor cells and mediates the differentiation and proliferation of stem cells. ${ }^{5}$ This receptor is activated by binding to its extracellular domain of the fms-related tyrosine kinase 3 ligand (FL), which induces the formation of homodimers in the plasma membrane and autophosphorylation. ${ }^{6}$ About 30 percent of all AML cases, (FLT3) gene mutations occur, with internal tandem duplication (ITD) being the mainly widespread form of FLT3 mutation which constitute about 25 percent from all cases of AML. ${ }^{7}$ FLT3-ITD has consistently been related to increased white blood cell levels, higher bone marrow (BM) cell counts, increased risk of relapse, and lower survival rates. ${ }^{8}$ These results indicate that the mutation of the FLT3-ITD gene plays an important role in the development of leukemia, rather than initiation.

The aim of this study is to investigate the characterization of NPM1 and FLT3-ITD mutations 
in Iraqi patients with AML and correlate the presence of these mutations with other clinical features and laboratory findings.

\section{Material and method}

After the approval of the Ethical Committee at Faculty of Biology, University of Baghdad and taking informed consents from the patients, the current experimental work was carried out at the Laboratory Department, Hematology Center and the National Center of Educational Laboratories at Medical City Complex, over a period extending from October 2019 till March 2020. A total of 58 patients, admitted to Baghdad Teaching Hospital, Medical City Complex, recently diagnosed with AML on the basis of findings of blood smear, bone marrow (BM) examination and flowcytometry immunophenotyping, were included in this study with an age ranged from 14 to 72 years in addition to another group of 25 apparently healthy individuals with an age ranging from 15 to 65 , those subjects were not found to have medical issues with normal investigations, therefore were used as normal controls for comparison with AML patients. A detailed information including residence, occupation, family history, past medical history, previous exposure to radiation or chemicals, smoking history and clinical presentation were collected from all patients and controls. The LeukoStrat ${ }^{\circledR}$ FLT3 Mutation kit (Cat No./ID: 9-412-0091, Invivoscribe) and ipsogen NPM1 MutaScreen Kit (Cat No./ID: 677013, Qiagen) were used to detection of FLT3-ITD and NPM1 mutations according to manufacturer's instructions. All Primers, materials and protocol were provided with the kits. Regarding molecular detection of FLT3-ITD and NPM1 mutations in brief; DNA was extracted using Qiagen extraction kit (Cat No./ID: 69504), FLT3ITD mutation was detected by conventional PCR (AppliedBiosystems) with gel electrophoresis. NPM1 mutation was investigated by real time PCR (Rotorgene Q). Hematological parameters were obtained by Nihon Khoden Celltac F Automatic CBC analyzer. Hematological parameters result that obtained were subjected to statistical analysis and $\mathrm{p}<0.05$ was considered significant.

\section{Results}

This study was conducted on 58 patients with AML and 25 healthy subjects all of them were selected randomly in relation to age and sex. the age of patient ranged from $14-72$ years, of median age of 30.5 years, and a mean of 42.9 years, 31 patients were male and 27 were female with a male to female ratio of $1: 14.1$ While in control group the age ranged from $(15-65$ years, with a median of 26 years and a mean of 30.6 years, 12 were males and 13 were female and as shown in figure (1) and table (1).

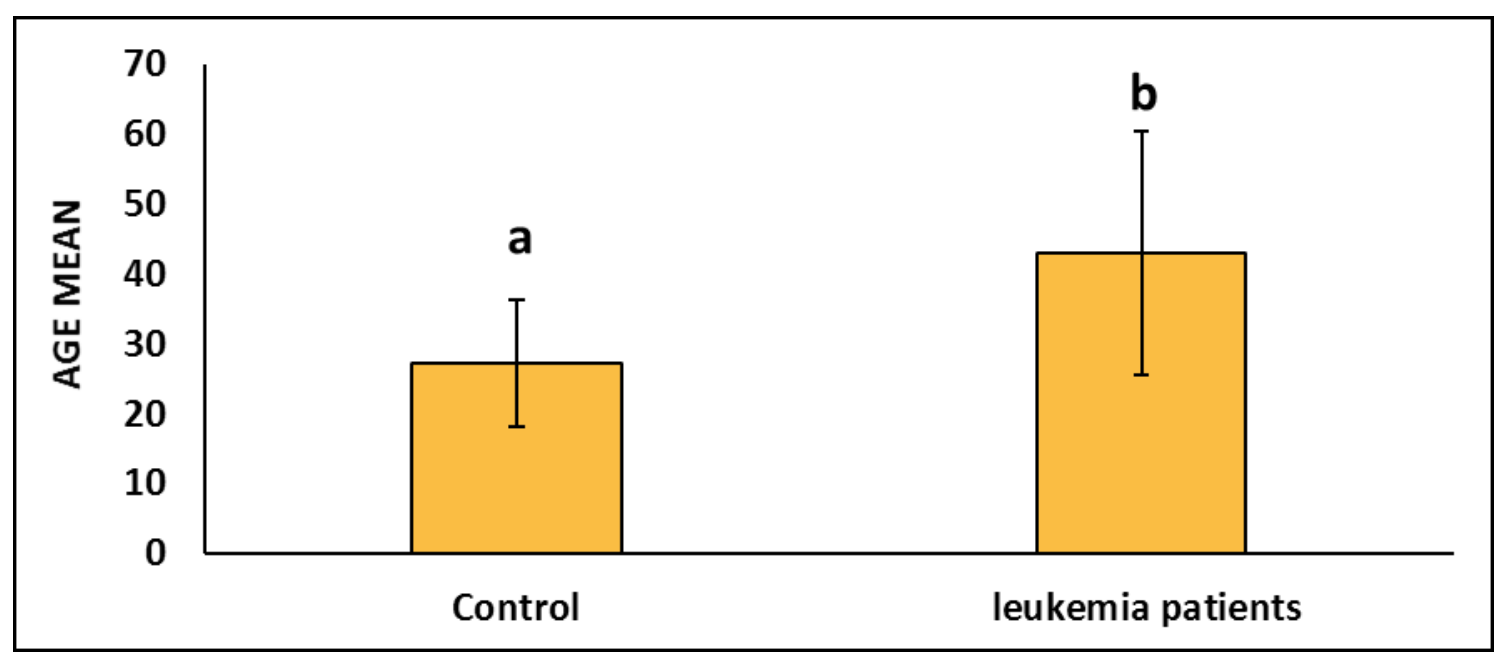

Figure 1: Age mean of acute myeloid leukemia patients and control. Different letters represent a significant difference between the means $(p<0.001)$. 
Table 1: Gender distribution in leukemic patients and controls.

\begin{tabular}{|l|c|c|c|c|}
\hline \multirow{2}{*}{ Gender } & \multicolumn{2}{|c|}{ Leukemia Patients $(\mathbf{N}=\mathbf{5 8})$} & $\mathbf{N}$ & Control (N= 25) \\
\cline { 2 - 5 } & $\mathbf{N}$ & $\mathbf{\%}$ & 12 & 48 \\
\hline Male & 31 & 53.45 & 13 & 52 \\
\hline Female & 27 & 46.55 & \multicolumn{1}{c|}{ Pearson's $\chi^{2}=0.208 ;$ D.F. $=3 ; \mathrm{p}=0.649$ (NS) } \\
\hline Statistical Analysis & \multicolumn{3}{|c|}{} \\
\hline
\end{tabular}

NS: Not significant $(\mathrm{p}>0.05)$.

FLT3-ITD mutation was detected in 10 out of 58 AML patients (17.24\%) while NPM1 mutation was detected in 6 patients $(10.34 \%)$ and as shown in table (2). FLT3-ITD mutation was detected in 7 (12.1\%) females and in $3(5.2 \%)$ males, on the other hand, NPM1 mutation was positive in $5(8.6 \%)$ males and in $1(1.7 \%)$ female as in table (2). The most common AML subtype according to FAB classification was AML-M5 which constitute about $18(31.03 \%)$ of the patients followed by AML- M2 in 14 (24.13\%), and as shown in table (2). Most of the patients are presented with pallor which was seen in $35(60.34 \%)$ of them followed by fever in $22(37.9 \%)$ and bleeding in17 (29.31\%) as shown in table (2).

Table 2: FLT3-ITD and NMP1 Mutations relation to the characteristic of AML patients.

\begin{tabular}{|c|c|c|c|c|c|c|c|c|c|}
\hline \multirow{3}{*}{\multicolumn{2}{|c|}{ Characteristics }} & \multicolumn{6}{|c|}{ Type of AML (58) } & \multirow{3}{*}{\multicolumn{2}{|c|}{ Total }} \\
\hline & & \multicolumn{2}{|c|}{ NPM1 (+ve) } & \multicolumn{2}{|c|}{ FLT3-ITD (+ve) } & \multicolumn{2}{|c|}{ AML Patients } & & \\
\hline & & $\mathbf{N}$ & $\%$ & $\mathbf{N}$ & $\%$ & $\mathbf{N}$ & $\%$ & & \\
\hline \multicolumn{2}{|c|}{ Frequency of Mutations } & 42 & 72.14 & 10 & 17.24 & 6 & 10.34 & \multicolumn{2}{|c|}{58} \\
\hline \multirow{2}{*}{ Gender } & \multirow{2}{*}{$\begin{array}{c}\text { Male } \\
\text { Female }\end{array}$} & 26 & 44.83 & 3 & 5.2 & 5 & 8.6 & \multicolumn{2}{|c|}{34} \\
\hline & & 16 & 27.59 & 7 & 12.1 & 1 & 1.7 & \multicolumn{2}{|c|}{24} \\
\hline \multicolumn{2}{|c|}{ FAB subtype } & \multicolumn{2}{|c|}{ AML Patients } & \multicolumn{2}{|c|}{ FLT3-ITD (+ve) } & \multicolumn{2}{|c|}{ NPM1 (+ve) } & Total & $\%$ \\
\hline \multicolumn{2}{|c|}{ M0 } & \multicolumn{2}{|c|}{9} & \multicolumn{2}{|c|}{1} & \multicolumn{2}{|c|}{1} & 11 & 18.97 \\
\hline \multicolumn{2}{|c|}{ M1 } & \multicolumn{2}{|c|}{2} & \multicolumn{2}{|c|}{1} & \multicolumn{2}{|c|}{1} & 4 & 6.9 \\
\hline \multicolumn{2}{|c|}{ M2 } & \multicolumn{2}{|c|}{12} & \multicolumn{2}{|c|}{2} & \multicolumn{2}{|c|}{0} & 14 & 24.14 \\
\hline \multicolumn{2}{|c|}{ M3 } & \multicolumn{2}{|c|}{0} & \multicolumn{2}{|c|}{0} & & & 0 & 0 \\
\hline & & & & & & & & 10 & 17.24 \\
\hline & & & & & & & & 18 & 31.03 \\
\hline & & & & & & & & 1 & 1.72 \\
\hline & & & & & & & & 0 & 0 \\
\hline & & & & & AML I & $(58$ & & & \\
\hline C & thaturint & & & & & & & & \\
\hline & & & & & & & & & \\
\hline & & & & & & & & & \\
\hline & & & & & & & & & \\
\hline & & & & & & & & & \\
\hline & & & & & & & & & \\
\hline & & & & & & & & & \\
\hline & & & & & & & & & \\
\hline $\mathrm{We}$ & loos & & & & & & & & \\
\hline & sion & & & & & & & & \\
\hline
\end{tabular}


Regarding the bone marrow blast cells percentage mean was $74 \pm 0.13$ in patients with FLT3-ITD mutation, $66 \pm 0.10$ in patients with NPM1 mutation and $62 \pm 0.22$ in non-mutant patients as shown in figure (2). Regarding the relation of FLT3-ITD and NPM1 mutation to hematological parameter of the patients, the mean WBC count in NPM1 was $(49.56 \pm 15.77 \times 10 * 9 / \mathrm{L})$ which was significantly higher than inpatients without the mutation for NPM1 \& FLT3-ITD $\left(29.36 \pm 16.52 \times 10^{*} 9 / \mathrm{L}\right)$ and as shown in figure (3).

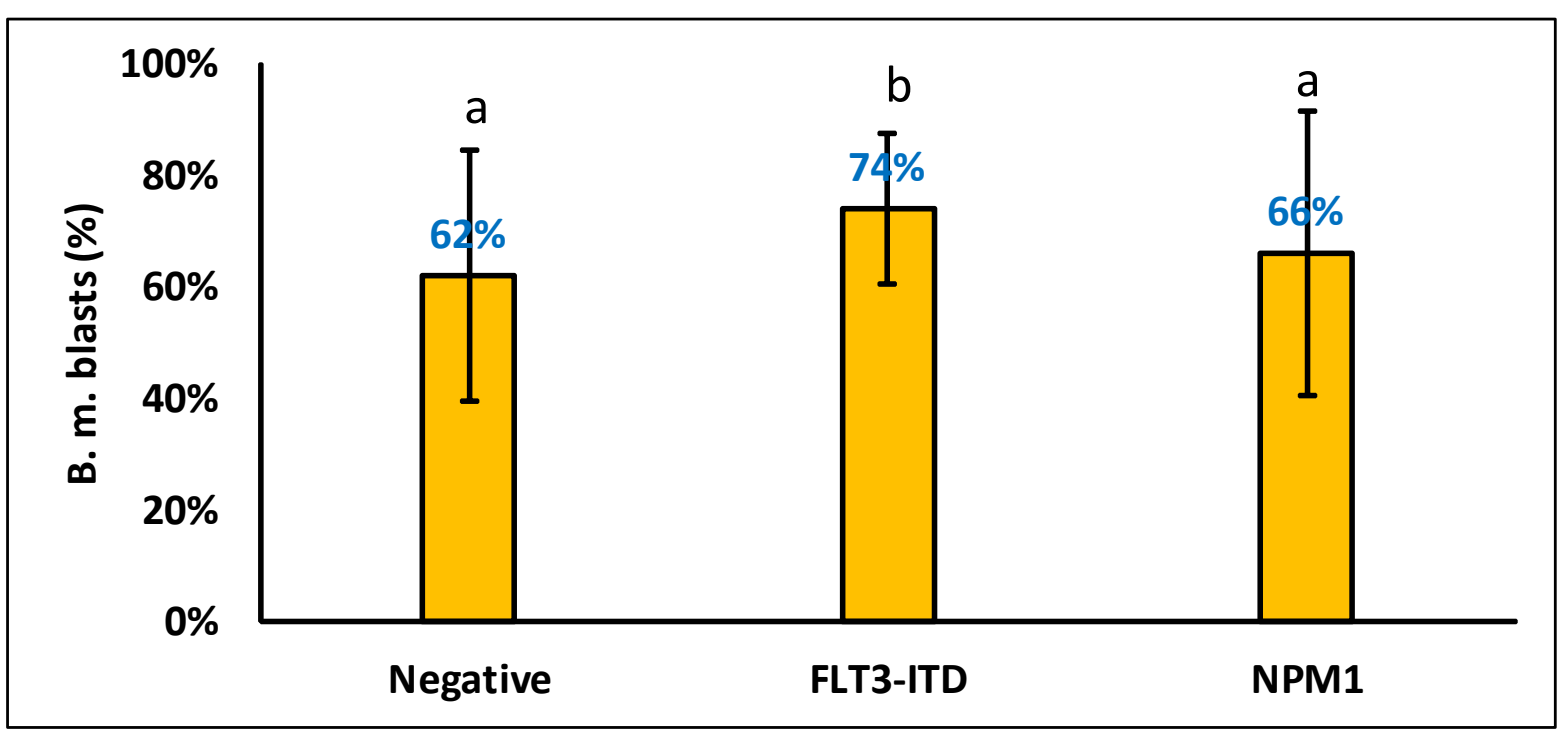

Figure 2: Mean of bone marrow blasts percentage among AML patients. Different letters (a and b) on the error bars indicate significant differences $(p<0.05)$, while similar letters represent no significant difference between means $(p>0.05)$.

A

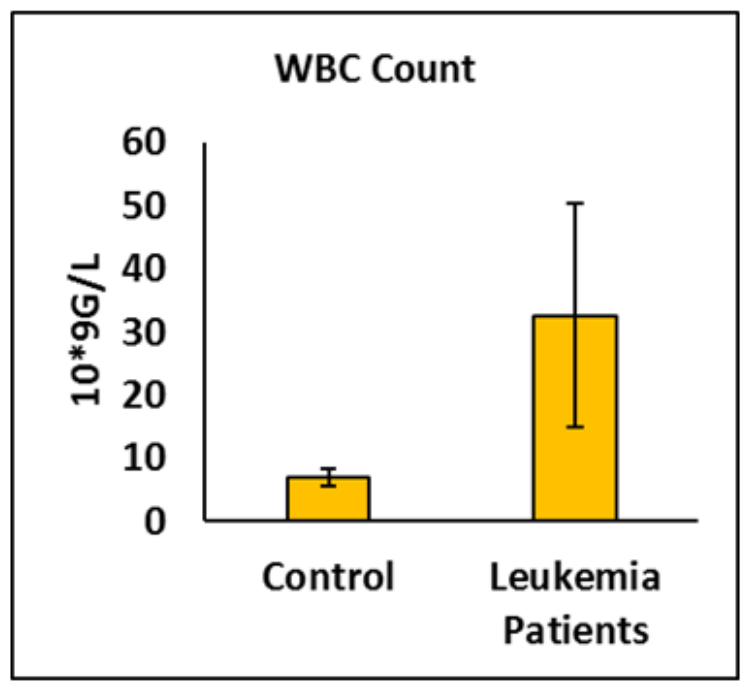

B

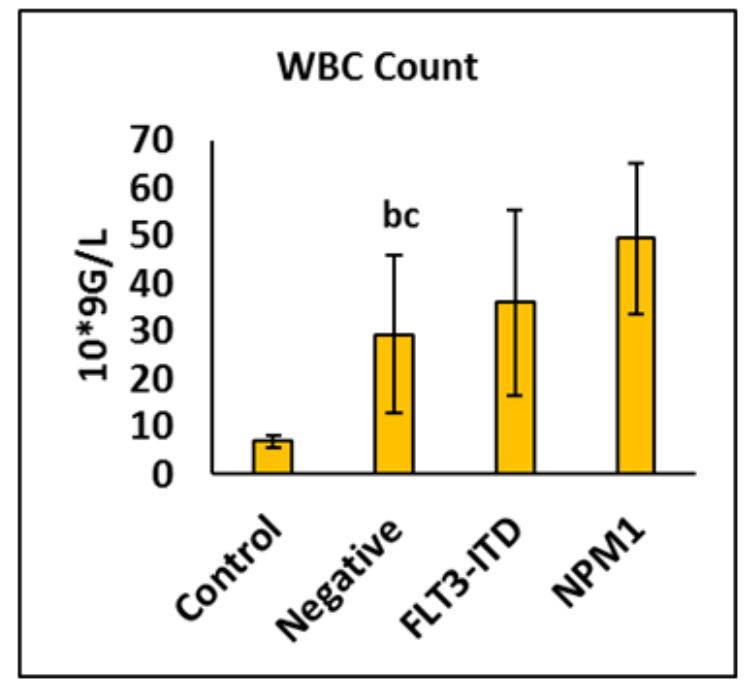

Figure 3: Evaluation of WBC count in AML Patients. A. WBCs in AML patient and control samples. B. WBC count of leukemia patients in relation to presences of mutations. Different letters $(a, b, c$ and d) on the error bars indicate significant differences $(\mathbf{p}<0.05)$.

Regarding RBC count, $\mathrm{Hb}$ level and platelets count, there was no significant correlation with FLT3-ITD and NPM1 mutations as shown in table (3). 
Table 3: Hematological parameters of AML patients in relation to mutations and control.

\begin{tabular}{|c|c|c|c|c|}
\hline \multirow{2}{*}{ Groups } & $\operatorname{RBC}(10 * 9 / L)$ & HGB (g/dL) & PLT $(10 * 9 / L)$ & \multirow{2}{*}{ P Value } \\
\hline & $\operatorname{Mean} \pm$ SD & Mean \pm SD & Mean \pm SD & \\
\hline Control & $4.91 \pm 0.69$ & $13.56 \pm 1.8$ & $261.52 \pm 68.97$ & NS \\
\hline AML Patients & $2.56 \pm 0.90$ & $7.56 \pm 2.45$ & $102.63 \pm 60.19$ & NS \\
\hline FLT3-ITD & $2.36 \pm 0.50$ & $7.5 \pm 1.85$ & $78.8 \pm 42.21$ & NS \\
\hline NPM1 & $2.68 \pm 0.41$ & $8.03 \pm 1.32$ & $95.17 \pm 60.49$ & NS \\
\hline
\end{tabular}

The Data is presented as the mean \pm SD. NS: Not significant $(\mathrm{p}>0.05)$.

\section{Discussion}

Acute myeloid leukemia is a heterogeneous disease results from mutation in a multipotent hematopoietic stem cell. It is a common malignant myeloid disorder in adults. ${ }^{9}$ A total 58 AML patients were enrolled in this study, the mean age was 42.9 years, comparable to Tawfiq et al ${ }^{10}$ with a mean age of 42 years. Male to female ratio was $1.14: 1$ which agrees with Figueroa et $\mathrm{al}^{11}$ and Dhahi et $\mathrm{al}^{12}$ who reported male to female ratio of 1.2: 1 for both, this slight male predominance could be due to being more exposed to environmental carcinogenic risks than females. FLT3-ITD mutation was detected in $(17.24 \%)$ of our patients similar to Yusoff et $\mathrm{al}^{13}$ where (16.1\%) of their patients had the mutation. Female have FLT3-ITD mutation more than male, in (12.1\%) and (5.2\%), respectively, comparable to Juliusson et al ${ }^{14}$ with detectable mutation in $(29 \%)$ of female and (22\%) of males. However, Chauhan et $\mathrm{al}^{15}$ disagree in reporting FLT3-ITD mutation in males more than females. NPM1 mutation was found in $(10.34 \%)$ of the patients and this was not so far from Abdulateef et $\mathrm{al}^{16}$ who detected it in $(18.86 \%)$ of the patients. NPM1 mutation was reported more in males in (16.1\%) of them than in females (3.7\%), this results are similar to Abdulateef et a ${ }^{16}$ with a detection in $(28.1 \%)$ of males and $(4.7 \%)$ of females. On the other hand, this differs from Dhahir and Dhahi ${ }^{17}$ who reported NPM1 mutation in $(60 \%)$ of females more than seen in males (37.5\%). The variation of results between studies may be due to possible differences in sample size as well as different method that have been used to evaluate these mutations. Regarding morphology, AML-M5 was the most common FAB subtype constitutes $(31.03 \%)$ of the cases followed by AML-M2 (24.13\%), parallel to Govedarovic and Marjanovic, 2011cK. ${ }^{18}$ On the other hand, this results are different from Khan, $2018^{19}$ where AML-M2 was reported in (59\%). However, study the subtype of AML is very important because it help to choose the best treatment and also affects a patient's outlook. For instance, the acute promyelocytic leukemia (APL) subtype is often treated using drugs that are different from those used for other subtypes of AML. ${ }^{20}$ Pallor was the most common presentation followed by fever, equivalent to findings of Dhahi et a ${ }^{12}$ but different from Chauhan et $\mathrm{al}^{15}$ which hepatosplenomegaly was the common clinical feature followed by lymphadenopathy. This variation may be due to the different immunological and physiological status of individuals among different populations. Patients with FLT3-ITD mutation had significantly higher mean B.M. blast cell percentage of (74\%)when compared with NPM1 mutation and AML without these mutations in (66\%) and (62\%), respectively. This close to Notopuro et $\mathrm{al}^{21}$ with blast cells of (79.5\%). Patients with NPM1 mutation had significantly higher WBC count mean $\left(49.56 \pm 15.77 \times 10^{*} 9 / \mathrm{L}\right)$ as compared with AML without any mutation $(29.36 \pm 16.52 \times 10 * 9 / \mathrm{L})$ similar to findings of Döhner et al and ${ }^{22}$ but different from Abdulateef et $\mathrm{al}^{16}$ which reported that WBC count was non-significantly higher than in non-mutated group. Despite low mean of RBC count, hemoglobin levels and platelets count in AML patients, there were no significant difference among different groups, low levels of these parameters is a logical consequence with AML which is a cancer of the myeloid linage of blood cells, characterized by the rapid growth of abnormal cells that impede normal blood cell production and this will cause anemia, pallor and bleeding tendency. Indeed, study the features of BM blasts may not only allow us to better know the biology circulation of bone marrow blasts, but may also help in better understanding and developing a new strategy of therapeutic. ${ }^{21}$ Also, many studies have shown that genotypic subgroup and WBC count without FLT3-ITD are independent predictors of effect. However, the correlation between the WBC count and 
the molecular markers including NPMc and FLT3-ITD on outcome of patients is still not clear ${ }^{18}$.

\section{Conclusion}

AML is common in middle age group with slight male predominance, AML-M5 was the most common FAB subtype, most of the patients presented with pallor, patients with NPM1 mutation had significantly higher WBC counts while patients with FLT3-ITD mutation have higher blast percentage comparableto other local and worldwide reports.

Conflict of Interest: None

Funding: Self

Ethical Clearance: Not required

\section{References}

1. Li Y, Xu Q, Lv N, Wang L, Zhao H, Wang X, Guo J, Chen C, Li Y, Yu L. Clinical implications of genome-wide DNA methylation studies in acute myeloid leukemia. Journal of hematology \& oncology. 2017 Dec;10(1):1-0.

2. Bănescu C, Skrypnyk C. The Value of FLT3, NPM1 and DNMT3A Gene Mutation Analysis in Acute Myeloid Leukemia Diagnosis. Revista Romana de Medicina de Laborator. 2019 Jul 1;27(3):239-43.

3. López DJ, Rodríguez JA, Bañuelos S. Nucleophosmin, a multifunctional nucleolar organizer with a role in DNA repair. Biochimica et Biophysica Acta (BBA)-Proteins and Proteomics. 2020 Aug 25:140532.

4. Falini B, Mecucci C, Tiacci E, Alcalay M, Rosati R, Pasqualucci L, La Starza R, Diverio D, Colombo E, Santucci A, Bigerna B. Cytoplasmic nucleophosmin in acute myelogenous leukemia with a normal karyotype. New England Journal of Medicine. 2005 Jan 20;352(3):254-66.

5. Bullinger L, Döhner K, Kranz R, Stirner C, Fröhling S, Scholl C, Kim YH, Schlenk RF, Tibshirani R, Döhner H, Pollack JR. An FLT3 gene-expression signature predicts clinical outcome in normal karyotype AML. Blood. 2008 May 1;111(9):44905.

6. Rivera-Torres N, Banas K, Kmiec EB. Modeling pediatric AML FLT3 mutations using CRISPR/ Cas12a-mediated gene editing. Leukemia \& Lymphoma. 2020 Aug 18:1-1.
7. Daver N, Schlenk RF, Russell NH, Levis MJ. Targeting FLT3 mutations in AML: review of current knowledge and evidence. Leukemia. 2019 Feb;33(2):299-312.

8. Döhner K, Thiede C, Jahn N, Panina E, Gambietz A, Larson RA, Prior TW, Marcucci G, Jones D, Krauter J, Heuser M. Impact of NPM1/FLT3ITD genotypes defined by the 2017 European LeukemiaNet in patients with acute myeloid leukemia. Blood, The Journal of the American Society of Hematology. 2020 Jan 30;135(5):37180.

9. Liu Y, He P, Liu F, Shi L, Zhu H, Zhao J, Wang $\mathrm{Y}$, Chen X, Zhang M. Prognostic significance of NPM1 mutations in acute myeloid leukemia: A meta-analysis. Molecular and clinical oncology. 2014 Mar 1;2(2):275-81.

10. Tawfiq SA, Yassin AK, AlGetta HA, Hasan KM. Acute myeloblastic leukemia: Important clinical and epidemiological facts from Hiwa Hospital in Sulaimaniyah, Iraq. Iraqi Journal of Hematology. 2019 Jul 1;8(2):69.

11. Figueroa ME, Lugthart $\mathrm{S}$, Li Y, ErpelinckVerschueren C, Deng X, Christos PJ, Schifano E, Booth J, van Putten W, Skrabanek L, Campagne F. DNA methylation signatures identify biologically distinct subtypes in acute myeloid leukemia. Cancer cell. 2010 Jan 19;17(1):13-27.

12. Dhahi MA, Al-Mudallel SS, Dhahir EK. The frequency of FLT3 mutation in fifty five Iraqi adult patients with acute myeloid leukemia. Iraqi Journal of Medical Sciences. 2012;10(2):140-7.

13. Yusoff YM, Seman ZA, Othman N, Kamaluddin NR, Esa E, Zulkiply NA, Abdullah J, Zakaria Z. Identification of FLT3 and NPM1 Mutations in Patients with Acute Myeloid Leukaemia. Asian Pacific journal of cancer prevention: APJCP. 2019;20(6):1749.

14. Juliusson G, Jädersten $M$, Deneberg $S$, Lehmann S, Möllgård L, Wennström L, Antunovic P, Cammenga J, Lorenz F, Ölander E, Lazarevic VL. The prognostic impact of FLT3-ITD and NPM1 mutation in adult AML is age-dependent in the population-based setting. Blood advances. 2020 Mar 24;4(6):1094-101.

15. Chauhan PS, Ihsan R, Singh LC, Gupta DK, Mittal $\mathrm{V}$, Kapur S. Mutation of NPM1 and FLT3 genes in acute myeloid leukemia and their association with 
clinical and immunophenotypic features. Disease markers. 2013 Jan 1;35.

16. Abdulateef S, Almothaffar A, Al-khafaji KR. Molecular Study of NPM1-A (Nucleophosmin1-A) Mutation in Iraqi Adult Acute Myeloid Leukemia Patients; Its Correlation with Clinicopathological Parameters. American Journal of Internal Medicine. 2017 Apr 19;5(3):37-40.

17. Dhahir EK, Dhahi MA. High frequency of nucleophosmin mutations in thirty two Iraqi adult patients with acute myeloid leukemia. Int J of App Sci Tech. 2012 May; 2(5):97-105.

18. Govedarovic N, Marjanovic G. Frequency and prognostic impact of FLT3/ITD mutation in patients with acute myeloid leukaemia. J BUON. 2011 Jan 1;16(1):108-11.

19. Khan MI. Acute Myeloid Leukemia: Pattern of Clinical and Hematological Parameters in a Tertiary
Care Centre. International Journal of Pathology. 2018:58-63.

20. Kumar CC. Genetic abnormalities and challenges in the treatment of acute myeloid leukemia. Genes \& cancer. 2011 Feb;2(2):95-107.

21. Notopuro PB, Nugraha J, Utomo B, Notopuro H. The Association of FLT3-ITD Gene Mutation with Bone Marrow Blast Cell Count, CD34, Cyclin D1, Bcl-xL and hENT1 Expression in Acute Myeloid Leukemia Patients. Iranian Journal of Pathology. 2020;15(4):306.

22. Döhner K, Schlenk RF, Habdank M, Scholl C, Rücker FG, Corbacioglu A, Bullinger L, Fröhling S, Döhner H. Mutant nucleophosmin (NPM1) predicts favorable prognosis in younger adults with acute myeloid leukemia and normal cytogenetics: interaction with other gene mutations. Blood. 2005 Dec 1;106(12):3740-6. 